\title{
EFFECT OF GRINDING UPON THE APPARENT DENSITY OF LEAD OXIDES
}

\author{
BY O. W. BROWN, S. V. COOK AND J. C. WARNER
}

The apparent density of lead oxides is recognized as an important factor in their use in the manufacture of storage battery plates: It has been noted in a previous article by Brown and Nees ${ }^{1}$ that grinding in a pebble mill has an effect on the apparent density of lead oxides. An oxide which is worthless for use in the manufacture of plates, if ground in a pebble mill under such conditions that its apparent density is increased, can be used in the production of very satisfactory storage battery plates.

The influence of grinding is not the same upon all oxides. Coarse crystalline oxides, on grinding, at first show a decrease in apparent density, but with further grinding again show a greater apparent density. A light amorphous oxide steadily increases in apparent density when subjected to grinding in a pebble mill.

In this investigation, the Abbe Trojan Mill was used for the grinding. The outside measurements of the porcelain jar were 8.75 by 9.75 inches. The flint pebbles ranged approximately, from one-half to one inch in diameter, and had a combined weight of 1,033 grams. The mill was

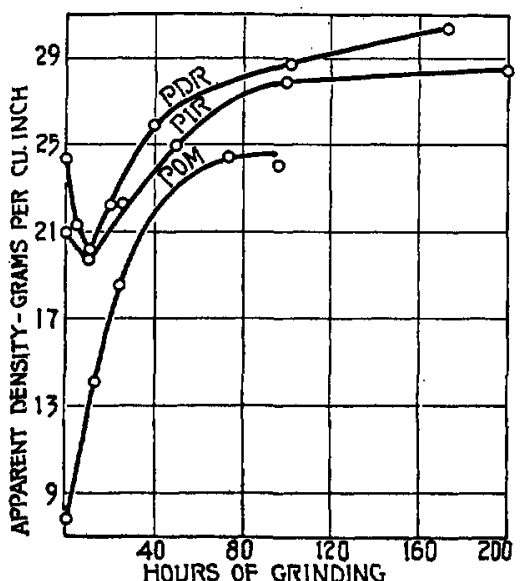

Fig. 1 adjusted so as to revolve 50 times a minute. In order to obtain equal grinding in all parts of the load, the mill was stopped every two hours and the contents scraped down from

${ }^{1}$ Jour. Ind. Eng. Chem., 4, Dec, 1912. 
the walls of the porcelain jar with an aluminum spoon. The load consisted of about 1800 grams of the oxide except when an extremely light oxide was being ground.

The apparent density of the oxides was determined before grinding and after various intervals of grinding. The Scott Volumeter was used in all apparent density determinations. The results obtained were plotted using hours as abscissae and grams per cubic inch as ordinates. The lead oxides used in this investigation were obtained through the courtesy of the Picher Lead Co.

The first oxide investigated was a red lead (Sample P. D. R.) which, by microscopic examination, was shown to be of a coarse crystalline nature. It was made from yellow litharge and had an apparent density of 24.34 grams per cubic inch before grinding. The results of experiments showing the effect of grinding on the apparent density of this oxide are given in Table $\mathrm{I}$.

TABLE I

Sample P. D. R.

\begin{tabular}{c|c}
\hline \hline Hours of grinding & $\begin{array}{c}\text { Apparent density } \\
\text { grams per cubic inch }\end{array}$ \\
\hline 0 & 24.34 \\
5 & 21.33 \\
10 & 20.10 \\
20 & 22.22 \\
40 & 25.88 \\
102 & 28.77 \\
173 & 30.45 \\
234 & 31.68
\end{tabular}

The results from Table I are shown graphically in the accompanying figure.

From the results of these experiments, it can be seen that the apparent density of the oxide first decreases with grinding and passes through a minimum after ten hours. Further grinding causes a steady increase in apparent density until a practically constant value is reached after 234 hours.

The next oxide (Sample P. I. R.) subjected to grinding 
was a crystalline oxide made from "red" litharge. Its apparent density, before grinding, was 20.96 grams per cubic inch. The effect of grinding upon the apparent density of this oxide is shown by the results of the experiments given in Table II.

- TABLE II

Sample P. I. R.

\begin{tabular}{c|c}
\hline Hours of grinding & $\begin{array}{c}\text { Apparent density } \\
\text { grams per cubic inch }\end{array}$ \\
\hline 0 & 20.96 \\
5 & $21.71^{*}$ \\
10 & 19.77 \\
25 & 22.33 \\
50 & 25.01 \\
100 & 27.95 \\
200 & 28.52
\end{tabular}

From the results in Table II, it is evident that the apparent density of this oxide was affected by grinding in a manner very similar to Sample P. D. R. A minimum apparent density was obtained after 10 hours of grinding. Further grinding caused a regular increase in apparent density as the period of grinding was lengthened up to between 100 and 200 hours, after which, grinding had practically no effect upon the apparent density of the oxide.

The third oxide (Picher Orange Mineral) was a very light amorphous oxide made from "sublimed" litharge. Its ap-

TABLE III

Picher Orange Mineral.

\begin{tabular}{c|c}
\hline Hours of grinding & $\begin{array}{c}\text { Apparent density } \\
\text { grams per cubic inch }\end{array}$ \\
\hline 0 & 7.81 \\
13 & 14.15 \\
24 & 18.53 \\
74 & 24.52 \\
96 & 24.12
\end{tabular}

* This value is probably too high due to excessive packing of the oxide when falling through the volumeter and is not plotted on the curve by which the results from this table are graphically shown. 
parent density, before grinding, was 7.81 grams per cubic inch. The results of experiments showing the effect of grinding upon the apparent density of this oxide are given in Table III.

The data from this table are also shown graphically in the figure. The light amorphous oxide, used in these experiments does not pass through a minimum apparent density upon grinding as the heavy crystalline oxides do, but shows a regular increase in apparent density until a practically constant value is reached with between 74 and 96 hours of grinding.

The apparent densities of the oxides, before grinding and after various periods of grinding were also determined in a packed condition by the use of a jolting machine. Under these conditions, the apparent densities of the oxides show a similar variation upon grinding, but the results obtained are not in all cases as consistent as the results obtained by the use of the Scott Volumeter.

\section{Conclusions}

The apparent density of a heavy crystalline oxide, first becomes less upon grinding, but with further grinding increases.

After the minimum point is reached, the apparent density of a lead oxide increases rapidly at first, but gradually approaches a constant value.

The apparent density of a light amorphous oxide increases with grinding from the start.

Laboratory of Physical Chemistry,

Indiana University

Bloomington, Indiana 